\section{Factors influencing growth and intestinal parasitic infections in preschoolers attending philanthropic daycare centers in Salvador, Northeast Region of Brazil}

\author{
Crescimento linear e infecções parasitárias \\ intestinais em pré-escolares matriculados em \\ creches filantrópicas de Salvador, Nordeste \\ do Brasil
}

\author{
Rebecca L. Lander 1 \\ Alastair G. Lander 1 \\ Lisa Houghton 1 \\ Sheila M. Williams 2 \\ Hugo Costa-Ribeiro 3 \\ Daniel L. Barreto ${ }^{3}$ \\ Angela P. Mattos ${ }^{3}$ \\ Rosalind S. Gibson 1
}

\footnotetext{
${ }^{1}$ Department of Human Nutrition, University of Otago, Dunedin, New Zealand.

2 Department of Preventive and Social Medicine, University of Otago, Dunedin, New Zealand.

${ }^{3}$ Hospital Universitário Prof Edgard Santos, Universidade Federal da Bahia, Salvador, Brasil

Correspondence R. S. Gibson Department of Human Nutrition, University of Otago.

Union Street, Dunedin, Otago 9015, New Zealand. rosalind.gibson@otago.ac.nz
}

\begin{abstract}
Poor growth and intestinal parasitic infections are widespread in disadvantaged urban children. This cross-sectional study assessed factors influencing poor growth and intestinal parasites in 376 children aged three to six years in daycare centers in Salvador, in the Northeast Region of Brazil. Data was obtained from seven daycare centers on child weight, height, socio-economic status, health and intestinal parasites in stool samples. Prevalence of moderate underweight $(<-1 S D>-2 S D)$, wasting and stunting was $12 \%$, $16 \%$ and $6 \%$ respectively. Socioeconomic status, birth order, and maternal weight were predictors of poor anthropometric status. Almost 30\% of children were infected with more than one intestinal parasite. Helminths (17.8\%), notably Trichuris trichiura (12\%) and Ascaris lumbricoides (10.5\%), and protozoan Giardia duodenalis (13\%) were the most common types of parasites detected. One percent of children had hookworm and Cryptosporidium $s p$. and 25\% had nonpathogenic protozoan cysts. Boys from families with very low socio-economic status had lower linear growth and presented a greater risk of helminth infection. Deworming is considered an alternative for reducing the prevalence of intestinal parasitic infections in this age group.
\end{abstract}

Preschool Child; Child Day Care Centers; Parasites; Parasitic Intestinal Diseases

\section{Introduction}

Gastro-intestinal parasitic infections, including soil-transmitted helminths are widespread in crowded urban environments with poor sanitation 1. Therefore, it is not surprising that the risk of intestinal parasitic infection is particularly high in urban and periurban areas in the Northeast Region of Brazil, one of the poorest and most populous regions of this tropical country ${ }^{2}$. Preschool children living in such environments are especially vulnerable to helminth infections with Ascaris lumbricoides (roundworm) and Trichuris trichiura (whipworm) because of the increased activity of these species in potentially infective environments and lack of appropriate sanitary behavior ${ }^{3}$.

Pathogenic protozoan infections are also common in poor urban settings 3 . Children attending daycare centers are especially vulnerable to Giardia duodenalis and Cryptosporidium sp. because the primary mode of transmission of these organisms is fecal-oral 4 . Both helminth and protozoan infections have been linked with several adverse health consequences, notably impaired growth and deficiencies in vitamin $A$ and iron, induced by anorexia, nausea, diarrhea and vomiting, reductions in digestion and absorption, and enhanced nutrient loss 5,6. Our study therefore aimed to: (1) assess the prevalence of poor growth and gastro-intestinal parasites in a selected group of preschool children aged three 
to six years attending urban and periurban daycare centers in Salvador; and (2) explore the factors that might influence poor growth and intestinal parasitic infections.

\section{Methods}

\section{Study sites and participants}

This cross-sectional study was conducted between August and November 2010 in the capital of the State of Bahia, Salvador, a densely populated city with 2.6 million inhabitants. Despite the implementation of a city-wide sanitation intervention in the last decade, a number of areas still lack appropriate sanitation coverage. Seven philanthropic preschool daycare centers located in the city center and in periurban areas were selected to participate in this study. The periurban daycare centers are located approximately 20 kilometers north and north-east of the city centre. One periurban daycare is located within a large gated complex with separate buildings for preschool daycare and primary and secondary education. The other five periurban daycares were located within two kilometer radius of a large favela (shantytown) community with a population of 65,0007 , where residents live primarily in permanent houses with a concrete block or wooden structure and concrete, ceramic tile or earth flooring. All daycare centers are accessible by road, although transportation in the rainy season is hindered by heavy rains.

Children enrolled in the daycare centers (maximum class size of 25 children) were from low-income families and attended daycare five days per week, except during holidays, up until school age. All of the daycare centers provide breakfast, a mid-morning snack, lunch, an afternoon snack, and milk drink or soup before the children go home. Inclusion criteria for the study were apparently healthy children enrolled in three and four-year-old daycare classes for the 2010 school year (February to December). Of the 438 eligible children, parents/guardians authorized the participation of 376 children (86\%). Of this total, approximately 40 children were recruited from each of the five periurban favela daycare centers, yielding a total of 202 children. The remainder were recruited from the city daycare centers $(n=79)$ and the gated complex ( $n=95$ ). Reasons for non-participation included children on the roll who had already moved or were moving during the year $(n=16)$, children not attending daycare because of chronic illness $(n=3)$ and children whose parent/guardian refused consent $(n=43)$. Data was not collected on the families who refused their child's participation in the study.

The study protocol was approved by the Ethics Research Committees of the Federal University of Bahia (Universidade Federal da Bahia) and the University of Otago. Written approval to carry out the study was obtained from the following participating philanthropic organizations: Santa Casa de Misericordia, responsible for the city centre and five periurban favela daycare centers and Mansão do Caminho, responsible for the periurban gated daycare center. Informed written permission to participate in the study was given by the children's parents or primary guardians.

Assessment of children's socio-demographic situation and health status

Trained Brazilian nutritionists administered a pre-tested questionnaire with mothers or guardians at the daycare center. Data on parental education and occupation, sanitation, household assets and other household characteristics were obtained. An overall socio-economic status score was determined for each participant based on a model designed to assess the poverty level of Brazilian families living in poor urban areas 8 . Points were assigned for family and house size and structure, parental education and occupation, marital status, house ownership and household assets, toilet and sewage facilities, type of drinking water, availability of electricity, and susceptibility to flooding during heavy rain. Socioeconomic status scores were divided into two categories: extremely low $(\leq 34)$ and low $(\geq 35)$.

Information on the child's ethnicity and health status was also collected based on maternal reports of vitamin and/or mineral supplement usage, vaccinations, parasite control (deworming), number of child hospitalizations and reasons, and exposure to tobacco smoke. Responses were verified where possible by reviewing children's health cards.

\section{Assessment of growth}

Weight and height were measured with children wearing light clothes and no shoes by a trained anthropometrist (R.L.L.) using standardized techniques and calibrated equipment 9 . Measurements were taken in duplicate and a third measurement was taken if the difference between the first two exceeded the allowable difference 9. Zscores were calculated for height-for-age (HAZ), weight-for-age (WAZ), weight-for-height (WHZ), and body-mass-index (BMIZ) using updated US Centers for Disease Control and Prevention (CDC) 2000 growth reference data 10 . Children 
were classified as undernourished or moderately undernourished based on z-scores as an index of growth with a standard deviation (SD) of $<-2$ and $<-1 \geq-2$, respectively. Possible risk of overweight or overweight in children was based on BMIZ of $>1 \leq 2 \mathrm{SD}$ and $>2 \mathrm{SD}$, respectively, as defined by World Health Organization (WHO) 11.

\section{Collection and microscopic assessment of parasites in stool samples}

Labeled plastic stool collection containers and instructions were distributed by the daycare center coordinators to children's parents/guardians who were requested to bring the stool sample back to the daycare center the following morning. If the parent/guardian failed to return the child's stool sample, replacement containers were provided on up to three subsequent occasions. Single stool samples were obtained from 325 of the 376 participants (86\%). Samples were transported to the laboratory in a chilled box, where an aliquot of each stool sample (two to four grams) was homogenized in a $\sim 10 \mathrm{~mL}$ sodium acetate-acetic acid formalin (SAF) solution (Ft. Richard Laboratories, Auckland, New Zealand) by manual stirring with a plastic spatula. Next, a fecal concentrate of the SAF mixture was prepared using the standard formalin-ethyl acetate sedimentation concentration procedure 12 . A standard amount of sediment $(100 \mu \mathrm{L})$ from each fecal concentrate was placed onto a slide and examined under the microscope by an experienced microbiologist (A.G.L.) for the presence of helminthic and protozoan intestinal parasites. Trichrome stain microscopy examination was used to confirm the presence of Entamoeba histolytica/dispar cysts but it was not possible to ascertain the presence of pathogenic E. histolytica or non-pathogenic E. dispar cysts. The presence of other non-pathogenic protozoan cysts, such as Escherichia coli, Endolimax nana, Iodamoeba butschlii, and Chilomastix mesnili was also noted. A semi-quantitative egg-burden estimate of positive helminth samples was also determined based on the number of eggs counted during the microscopy examination. Light, moderate, and heavy loads were defined as $\leq 1$ egg, 2-9 eggs and $\geq 1$ egg per 10 low power magnification fields (10x), respectively. The microscopic examination of fecal concentrates was repeated on a random sub-sample ( $10 \%$ of the total sample) by a microbiologist not involved with this study to determine reproducibility of the methods.
Qualitative detection of Giardia and Cryptosporidium antigens in feces

A separate SAF aliquot ( $\sim 2 \mathrm{~mL})$ was used to detect the presence of Giardia and Cryptosporidium antigens using GIARDIA/CRYPTOSPORIDIUM CHEK, an in vitro enzyme-linked immunosorbent assay (ELISA) (TechLab Inc., Blacksburg, USA). This combined antigen assay uses monoclonal and polyclonal antibodies to cell-surface antigens of Giardia and an oocyst antigen of Cryptosporidium sp.; details of this method are given elsewhere 13. Samples that tested positive were re-tested, once with a Giardia-specific ELISA test and once with a Cryptosporidium-specific ELISA test according to the manufacturer's instructions, to determine whether the stool sample tested positive for Giardia, Cryptosporidium, or both protozoa.

\section{$\underline{\text { Statistical analysis }}$}

Selected sociodemographic and health characteristics of the children, parents and households are presented as a percentage for categorical variables and as a mean and SD for continuous variables. The mean (SD) of anthropometric variables for the children are summarized by sex.

Differences in age, anthropometric indices, sex, mother's education, socio-economic status, parasite control and use of vitamin A supplements between the participants who provided stool samples and those who did not were compared using a Student's t-test for the continuous variables and Fisher's exact test for the categorical variables.

Prevalence (95\% confidence interval-95\%CI) was calculated using Poisson distribution for frequencies of $<10$ for helminthic and protozoan intestinal parasites based on the results of the microscopic examination and the ELISA method used to detect G. duodenalis and Cryptosporidium sp. antigen. The daycare centers were divided into three groups: city centre, periurban favela and periurban gated, to analyze the association between prevalence of infection with helminths, selected protozoan intestinal parasites and nonpathogenic cysts with deworming treatment and use of vitamin A supplements using Fisher's exact test. Multiple linear regression analysis was used to examine the independent predictors of WAZ, WHZ, HAZ and BMIZ. Logistic regression models were used to examine the relationship between infection with helminths and G. duodenalis and the following factors: age 3.00 to 3.99 years and 4.00 to 5.65 years; sex, socioeconomic status (extremely low and low), deworming treatment and use of vitamin A supplements. The sandwich esti- 
mator was used to obtain robust standard errors to account for the sampling procedure. Statistical analysis was carried out using Stata version 11 (Stata Corp., College Station, USA).

\section{Results}

\section{Sociodemographic and health status}

The overall response rate from the daycare centers was 86\% (376/438) comprising 196 males and 180 females aged 3.00 to 5.65 years. The mean (SD) age of the children was 4.2 years $(0.61)$ and $66.2 \%(249 / 376)$ of the sample were first or second-born children. Six percent of the participants were white, $42.2 \%$ were black, and $51.8 \%$ were mixed race. Fourteen percent $(32 / 227)$ of children with known birth weight weighed less than 2,500g at birth.

Household sociodemographic characteristics are shown in Table 1. Forty-seven percent of fathers and $56 \%$ of mothers had primary school education, but only $3 \%$ of parents had concluded education beyond high school level. Mothers with low levels of education (no education or to primary school level) had significantly more children (three or more) $(\mathrm{p}<0.001)$. Almost $50 \%$ of fathers were regularly employed, whereas onethird of mothers were unemployed, with another third working as casual wage earners. Nearly $40 \%$ of mothers/guardians were single or divorced, $16 \%$ did not know paternal education level and $12 \%$ did not know the father's occupation. Overall, $60.5 \%$ of households received a monthly income of one minimum monthly salary ( $\$ 115$ Brazilian Reais) or less. The following means (SD) were observed for the different variables in mothers: age 29.7 (7.0) years; height $159.1 \mathrm{~cm}$ (6.7); weight $66.4 \mathrm{~kg}$ (15.4); and BMI $26.2 \mathrm{~kg} / \mathrm{m}^{2}$ (5.7). Fourteen percent of mothers/guardians had two or fewer meals per day according to the self reports.

The health characteristics of participants are shown in Table 2. Over half of the children in the sample (54.3\%) had received dietary supplements at some time, $19 \%$ had received iron syrup in the previous six months and $53 \%$ had taken vitamin A capsules at some time in their life. The use of dietary supplements was greatest in children attending the city centre daycare center $(\mathrm{p}=0.008)$; however the use of vitamin A supplements was most common among children attending the five periurban favela daycare centers ( $\mathrm{p}<0.001)$.

Most children (83.8\%) received routine childhood vaccinations, and coverage was found to be highest $(\mathrm{p}<0.001)$ among children attending the five periurban favela daycare centers. Fiftyone percent of children received parasite control
Table 1

Household sociodemographic characteristics $(n=376)$.

\begin{tabular}{|c|c|c|}
\hline & $\mathrm{n}$ & $\%$ \\
\hline \multicolumn{3}{|l|}{ Father's education } \\
\hline No schooling & 15 & 4.0 \\
\hline Primary school & 178 & 47.4 \\
\hline High school & 111 & 29.5 \\
\hline$>$ High school & 11 & 2.9 \\
\hline Unknown & 61 & 16.2 \\
\hline \multicolumn{3}{|l|}{ Mother's education } \\
\hline No schooling & 13 & 3.5 \\
\hline Primary school & 212 & 56.4 \\
\hline High school & 144 & 38.3 \\
\hline > High school & 7 & 1.8 \\
\hline \multicolumn{3}{|l|}{ Father's occupation } \\
\hline Regular wage earner & 170 & 45.2 \\
\hline Casual wage earner & 125 & 33.2 \\
\hline Business or trade owner & 11 & 2.9 \\
\hline Unemployed & 24 & 6.4 \\
\hline Unknown & 46 & 12.2 \\
\hline \multicolumn{3}{|l|}{ Mother's occupation } \\
\hline Regular wage earner & 81 & 21.5 \\
\hline Casual wage earner & 129 & 34.4 \\
\hline Business or trade owner & 5 & 1.3 \\
\hline Domestic worker & 35 & 9.3 \\
\hline Unemployed & 126 & 33.5 \\
\hline Total income $(\leq \mathrm{R} \$ 415)$ & 227 & 60.5 \\
\hline \multicolumn{3}{|l|}{ Mother's marital status } \\
\hline Married/Partner & 228 & 60.6 \\
\hline Divorced & 13 & 3.5 \\
\hline \multirow[t]{2}{*}{ Single } & 135 & 35.9 \\
\hline & $\mathbf{n}$ & Mean (SD) \\
\hline Maternal age (years) & 368 & $29.7(7.0)$ \\
\hline Maternal height (cm) & 312 & $159.1(6.7)$ \\
\hline Maternal weight (kg) & 324 & $66.415 .4)$ \\
\hline Maternal BMI & 312 & $26.2(5.7)$ \\
\hline
\end{tabular}

BMI: body mass index.

(deworming) within the six months prior to the questionnaire, with treatment being more frequent among children enrolled at the periurban gated daycare center $(p=0.004)$. Fifty percent of children had been hospitalized at least once, and $25.7 \%$ had been hospitalized three times or more. Upper respiratory infections accounted for almost half $(49.7 \%)$ of hospitalizations, whereas hospitalization due to diarrheal episodes was much less frequent $(8.6 \%)$. The presence of a regular adult smoker was reported in almost a 
Table 2

Health characteristics of preschoolers $(n=376)$

\begin{tabular}{lcc}
\hline & $\mathbf{n}$ & $\%$ \\
\hline Dietary supplements & 204 & 54.3 \\
Vitamin A & 200 & 53.2 \\
Iron syrup in the previous 6 months & 70 & 18.6 \\
Vaccinations & 315 & 83.8 \\
BCG & 281 & 74.7 \\
Polio & 291 & 77.4 \\
DPT (Diphtheria, Pertussis, Tetanus) & 288 & 76.8 \\
Measles & 272 & 72.3 \\
Rotavirus & 197 & 52.4 \\
Pneumococcus & 7 & 1.9 \\
Influenza A (H1N1) & 133 & 35.4 \\
Deworming treatment & 192 & 51.1 \\
Hospitalizations & 187 & 49.7 \\
Once to twice & $139 / 187$ & 74.3 \\
Three times or more & $48 / 187$ & 25.7 \\
Reasons for hospitalizations & & \\
Diarrhea & $16 / 187$ & 8.6 \\
Upper respiratory infection & $93 / 187$ & 49.7 \\
Other reasons & $78 / 187$ & 41.7 \\
Smoking & & \\
Mother smoking in the house & 47 & 12.5 \\
Adult smoking in the house & 89 & 23.7 \\
History of asthma in mother or sibling & 68 & 18.1 \\
\hline
\end{tabular}

quarter of households $(23.7 \%)$, and $12.5 \%$ of mothers smoked at home.

\section{Anthropometry}

Table 3 presents the mean (SD) anthropometric $\mathrm{z}$-scores for the children and differences by sex. Boys had significantly lower z-scores for heightfor-age, weight-for-age, weight-for-height, and BMI than girls. No significant differences were observed by age group.

Although $5.5 \%(20 / 364)$ of children had a HAZ below $-1>-2 \mathrm{SD}$, very few children $(1.9 \%$; $7 / 364)$ were stunted (HAZ < -2SD). Less than $2 \%$ (7/364) of the children were underweight (i.e., WAZ <-2SD), but $12.1 \%(44 / 364)$ were moderately underweight (i.e., WAZ $<-1 \geq-2 S D$ ). Although few children $(5.2 \%$; $19 / 363)$ were wasted $(\mathrm{WHZ}<$ -2SD), $15.7 \%(57 / 363)$ were moderately wasted (i.e, WHZ $<-1 \geq-2 \mathrm{SD}$ ). Risk of overweight in children was $10.7 \%$ (39/364), based on a BMIZ > $1 \leq$ 2SD; $2.5 \%$ (9/364) of children were overweight (i.e., BMIZ > 2SD).

\section{Prevalence of parasitic infections}

Of the 376 participants, 325 (86\%) provided stool samples. No significant differences in age, anthropometric indices, sex, mother's education, socio-economic status, and de-worming treatment were found between participants providing a stool sample and those participants who did not $(n=51)$, with the exception of the use of vitamin A supplements. Prior use of vitamin A supplements in children who provided a stool sample was greater than in those who did not $(\mathrm{p}=0.016)$.

The prevalence of helminthic and protozoan intestinal parasites (Giardia sp. and Cryptosporidium sp. antigens) is presented in Table 4. Almost 30\% (95/325) of participants were infected with at least one intestinal parasite and $25 \%(80 / 325)$ had non-pathogenic protozoan cysts. Two or more parasites were present in $9.2 \%$ (95\%CI: 6.3 ; 12.9) of children and $2.5 \%$ (95\%CI: $1.1 ; 4.9)$ of children were infected with three or more parasites. No Schistosoma species were found in the stool samples. 
Mean (SD) growth measurements and z-scores by sex in children.

\begin{tabular}{lccccc}
\hline Variable & $\mathbf{n}$ & Females & $\mathbf{n}$ & Males & Difference $(95 \% \mathrm{Cl})$ \\
\hline Birth weight $(\mathrm{g})$ & 104 & $3,055.5(573.4)$ & 123 & $3,215.4(633.0)$ & $159.89(-38.81 ; 358.59)$ \\
Birth length (cm) & 88 & $47.9(3.6)$ & 98 & $49.4(2.5)$ & $1.47(-0.17 ; 3.12)$ \\
WAZ & 171 & $0.21(0.99)$ & 193 & $0.07(1.05)$ & $-0.15(-0.28 ;-0.02)$ \\
WHZ & 170 & $-0.17(1.01)$ & 193 & $-0.29(1.06)$ & $-0.12(-0.23 ;-0.001)$ \\
HAZ & 171 & $0.60(1.03)$ & 193 & $0.37(1.08)$ & $-0.23(-0.42 ;-0.05)$ \\
BMI & 171 & $-0.11(1.12)$ & 193 & $-0.33(1.17)$ & $-0.23(-0.37 ;-0.08)$ \\
\hline
\end{tabular}

BMI: body mass index; HAZ: height-for-age; SD: standard deviation; WAZ: weight-for-age; WHZ: weight-for-height; $95 \% \mathrm{Cl}$ : $95 \%$ confidence interval.

Table 4

Prevalence $(\%$ and $95 \% \mathrm{Cl})$ of intestinal parasitic infection determined using microscopy and ELISA assay * $(n=325)$.

\begin{tabular}{lcc}
\hline Variable & $\mathbf{n}$ & $\%(95 \% \mathrm{Cl})$ \\
\hline Presence of parasites & 95 & $29.2(24.3 ; 34.5)$ \\
Presence of $\geq 2$ types of parasite & 30 & $9.2(6.3 ; 12.9)$ \\
Presence of $\geq 3$ types of parasite & 8 & $2.5(1.1 ; 4.9)$ \\
Helminths & 58 & $17.8(13.8 ; 22.5)$ \\
$\quad$ Trichuris trichiura & 39 & $12.0(8.7 ; 16.0)$ \\
Ascaris lumbricoides & 34 & $10.5(7.4 ; 14.3)$ \\
Hookworm & 3 & $0.9(0.2 ; 2.7)$ \\
Giardia duodenalis & 42 & $12.9(9.5 ; 17.1)$ \\
Entamoeba histolytica/dispar & 12 & $3.7(1.9 ; 6.4)$ \\
Cryptosporidium sp. & 1 & $0.3(0.01 ; 1.7)$ \\
Hymenolepsis nana & 1 & $0.3(0.01 ; 1.7)$ \\
Strongyloides stercoralis & 1 & $0.3(0.01 ; 1.7)$ \\
Presence of non-pathogenic cysts ** & 80 & $24.6(20.0 ; 29.7)$ \\
\hline
\end{tabular}

95\% Cl: 95\% confidence interval.

* ELISA assay for Giardia duodenalis and Cryptosporidium sp.

** Does not include Entamoeba dispar.

The most common helminth species found were T. trichiura and A. lumbricoides. Prevalence of hookworm infestation was very low $(0.9 \%$; 95\%CI: $0.2 ; 2.7)$. Prevalence of T. trichiura was highest in boys $(\mathrm{p}=0.016)$. Almost half of T. trichiura-infected children $(49 \%$; 19/39) had a light egg burden, 36\% (14/39) had a moderate egg load and $15 \%(6 / 39)$ had a heavy egg burden. The light, moderate and heavy egg burdens of children infected with A. lumbricoides was $50 \%$ (17/34), $26 \%$ (9/34) and $24 \%(8 / 34)$, respectively (results not shown). Fifteen children (5\%) were infected with both T. trichiura and A. lumbricoides. Hookworm infestation occurred in conjunction with either $T$. trichiura $(\mathrm{n}=2)$ or A. lumbricoides $(\mathrm{n}=1)$.

Infection with G. duodenalis was found in $12.9 \%$ (95\%CI: $9.5 ; 17.1)$ of stool samples. Four- teen children (4\%) had both G. duodenalis and helminths, with the presence of either T. trichiura $(\mathrm{n}=8)$, A. lumbricoides $(\mathrm{n}=3)$, or all three parasites simultaneously $(\mathrm{n}=3$ ) (results not shown). E. histolytica/dispar cysts were found in $3.7 \%$ (95\%CI: $1.9 ; 6.4)$ of the stool samples, of which approximately half $(n=5)$ were in conjunction with one or more helminths and/or G. duodenalis.

Frequency (\%) of parasite infections, deworming treatment and use of vitamin A supplements by daycare group is shown in Table 5 . Significant differences existed among the three daycare groups regarding frequency of infection with an intestinal parasite, specifically helminths and non-pathogenic cysts, and deworming and use of vitamin A supplements. In general, 
Table 5

Frequency (\%) of intestinal parasitic infection, deworming treatment and vitamin A supplementation by day care group $(n=325)$.

\begin{tabular}{|c|c|c|c|c|}
\hline Variable & $\begin{array}{l}\text { City centre } \\
(n=60)\end{array}$ & $\begin{array}{l}\text { Periurban favela } \\
\qquad(\mathrm{n}=185)\end{array}$ & $\begin{array}{l}\text { Periurban gated } \\
\qquad(\mathrm{n}=80)\end{array}$ & p-value \\
\hline Presence of parasites & $10(16.7)$ & $68(36.8)$ & $17(21.3)$ & 0.002 \\
\hline Helminth * & $4(6.7)$ & $43(23.2)$ & $11(13.8)$ & 0.007 \\
\hline Giardia duodenalis & $7(11.7)$ & $29(15.7)$ & $6(7.5)$ & 0.182 \\
\hline Entamoeba histolytica & $0(0.0)$ & $10(5.4)$ & $2(2.5)$ & 0.162 \\
\hline Non-pathogenic protozoa cysts & $6(10.0)$ & $56(30.3)$ & $18(22.5)$ & 0.004 \\
\hline Deworming treatment within 6 months & $26(43.3)$ & $91(49.2)$ & $52(65.0)$ & 0.020 \\
\hline Vitamin A supplementation: whether ever used & $35(58.3)$ & $121(65.4)$ & $25(31.3)$ & $<0.001$ \\
\hline
\end{tabular}

* Helminth includes: Trichuris trichiura, Ascaris lumbricoides and hookworm.

prevalence of intestinal parasitic infections was greatest among children attending the periurban favela daycare center. Deworming treatment was more frequent among children attending the periurban gated daycare $(65 \%)$, although only about a third of these children had taken vitamin A supplements.

Factors influencing poor growth and intestinal parasitic infection in preschoolers

Significant predictors of anthropometric z-scores identified by regression analysis differed by variable (Table 6). Helminth infection showed a significant inverse association with WAZ $(\mathrm{p}=0.018)$ and HAZ ( $\mathrm{p}=0.003$ ) using univariate analysis, but this association lost significance in multivariate analysis and was thus excluded. Infection with $G$. duodenalis was also excluded from the regression analysis because no significant negative association with growth indicators was found. A significant association was found between mother's weight, age and birth order and WAZ, between socio-economic status and WHZ and BMIZ, and between sex and HAZ. The association between socioeconomic status and WAZ and HAZ also showed a tendency to be significant. With regard to HAZ, sex and mother's height were significant predictors and socio-economic status and birth order tended to be significant. The logistic regression analysis (Table 7) showed that being male and from a family with extremely low socioeconomic status were significant risk factors for infection with helminths. Deworming was highly effective against helminth infection and the use of vitamin A supplements showed a modest inverse association with $G$. duodenalis infection.
Table 6

Multiple linear regression analysis using growth indices as dependent variables.

\begin{tabular}{llll}
\hline & $\beta$ coefficient & $95 \% \mathrm{Cl}$ & p-value \\
\hline WAZ ( $\mathrm{n}=313$ ) & & & \\
Sex (boys) & -0.11 & $-0.25 ; 0.03$ & 0.100 \\
Age (years) & -0.21 & $-0.40 ;-0.01$ & 0.039 \\
SES (extremely poor) & -0.22 & $-0.45 ; 0.02$ & 0.069 \\
Maternal weight (kg) & 0.02 & $0.02 ; 0.03$ & $<0.001$ \\
Birth order (more than 2) & -0.30 & $-0.54 ;-0.07$ & 0.019 \\
WHZ ( $\mathrm{n}=312$ ) & & & \\
Sex (boys) & -0.08 & $-0.21 ; 0.05$ & 0.184 \\
Age (years) & -0.15 & $-0.38 ; 0.09$ & 0.182 \\
SES (extremely low) & -0.31 & $-0.57 ;-0.05$ & 0.028 \\
Maternal weight (kg) & 0.02 & $0.01 ; 0.03$ & 0.002 \\
Birth order (more than 2) & -0.09 & $-0.30 ; 0.13$ & 0.359 \\
HAZ ( $\mathrm{n}=302$ ) & & & \\
Sex (boys) & -0.26 & $-0.35 ;-0.18$ & $<0.001$ \\
Age (years) & -0.08 & $-0.36 ; 0.20$ & 0.518 \\
SES (extremely low) & -0.19 & $-0.40 ; 0.01$ & 0.062 \\
Maternal height (cm) & 0.06 & $0.04 ; 0.08$ & $<0.001$ \\
Birth order (more than 2) & -0.26 & $-0.53 ; 0.01$ & 0.055 \\
BMI ( $\mathrm{n}=313$ ) & & & \\
Sex (boys) & -0.18 & $-0.32 ;-0.05$ & 0.015 \\
Age (years) & -0.08 & $-0.34 ; 0.19$ & 0.519 \\
SES (extremely low) & -0.35 & $-0.64 ;-0.06$ & 0.023 \\
Maternal weight (kg) & 0.02 & $0.01 ; 0.03$ & 0.002 \\
Birth order (more than 2) & -0.07 & $-0.29 ; 0.16$ & 0.515 \\
\hline
\end{tabular}

BMI: body mass index; HAZ: height-for-age; SES: socioeconomic status; WAZ: weight-forage; WHZ: weight-for-height; $95 \% \mathrm{Cl}$ : 95\% confidence interval. 
Logistic regression models of risk factors (by odds ratio and $95 \% \mathrm{Cl}$ ) for infection with helminths $(n=58)$ and Giardia duodenalis $(n=42)$.

\begin{tabular}{llllc}
\hline Risk factors & Helminths $(\mathbf{n}=\mathbf{5 8})$ & $\mathbf{p}$-value & G. duodenalis $(\mathbf{n}=\mathbf{4 2})$ & $\mathbf{p}$-value \\
\hline Age group (older group) & $1.09(0.59 ; 2.03)$ & 0.776 & $0.92(0.37 ; 2.33)$ & 0.866 \\
Sex (male) & $2.34(1.14 ; 4.82)$ & 0.021 & $1.15(0.67 ; 1.97)$ & 0.620 \\
SES (extremely low) & $2.04(1.33,3.13)$ & 0.001 & $2.02(0.87 ; 4.69)$ & 0.101 \\
Deworming treatment & $0.60(0.40 ; 0.91)$ & 0.015 & $1.13(0.51 ; 2.52)$ & 0.764 \\
Vitamin A supplementation & $0.67(0.29 ; 1.56)$ & 0.355 & $0.46(0.20 ; 1.03)$ & 0.061 \\
\hline
\end{tabular}

SES: socioeconomic status; $95 \% \mathrm{Cl}$ : $95 \%$ confidence internal.

\section{Discussion}

Our study highlights that there have been a number of improvements in the growth status of children from families with low socioeconomic status in Brazil over recent years. Prevalence rates for stunting, underweight and wasting among disadvantaged preschoolers were very low $(\leq 5 \%)$ when compared to earlier studies carried out in Brazil ( 16\%) 8,14. Prevalence of mild-to-moderate under nutrition was also low $(\sim 15 \%)$, and is similar to rates for toddlers from daycare centers in São Paulo in the Southeastern Region of Brazil, where families have a higher socioeconomic status 15 . Such improvements have been attributed to the expansion of healthcare and pro-poor social programs, together with increases in purchasing power and levels of maternal education among poor families 16,17 . Nevertheless, $~ 13 \%$ of the disadvantaged preschoolers that made up our sample were at risk of overweight or classified as overweight, emphasizing the importance of including nutrition education as a component of pro-poor social policies.

Despite improvements, poverty remains a major influencing factor affecting the growth status of these preschoolers. Anthropometric indices were lower in children living in households classified as extremely poor, indicating greater impairment of somatic and linear growth in these children than in their counterparts from better off families (Table 6). Such a marked affect was unexpected given that the weekly menus were the same for all children in the daycares studied. It is possible, however, that children from extremely impoverished households experience greater food quantity and/or quality deficits on weekends and during vacations compared to preschoolers from families with a higher socioeconomic status. These children's mothers reported eating fewer daily meals, had lower mean body weight and BMI $(\mathrm{p}<0.05)$ and had more children to feed than their counterparts from families with a higher socioeconomic status. Moreover, both maternal weight and height had a significant impact on anthropometric indices $(p<0.01)$. These findings emphasize the importance of continuing poverty reduction efforts to improve the standard of living of families with extremely low socioeconomic status.

Standard of living was also a significant risk factor for certain parasitic infections in these children, particularly helminths. Several other studies have documented a positive association between risk of helminth infection and extremely low socioeconomic status ${ }^{18}$. Of the helminths identified, A. lumbricoides and T. trichiura were the most prevalent; infection with hookworm was negligible $(<1 \%)$. Infection intensity for these two helminths $-A$. lumbricoides and $T$. trichiura - was moderate to heavy in $50 \%$ of the infected children contributing to an increased risk of morbidity 19. No significant association was found between age group and infection with helminths and other intestinal parasites, probably due to the narrow age range of the sample. The age range of the children and the setting may also explain the low prevalence of infection with hookworm and schistosomes as young children attending daycare centers in urban areas are less likely to be exposed to natural bodies of water than older children living in rural settings 20 .

The direction and strength of the association between infection with G. duodenalis and standard of living was consistent with an earlier study in Salvador 21; however, in contrast to helminths, no significant positive association was observed between infection with G. duodenalis and standard of living. Almost 13\% of preschoolers were infected with these waterborne protozoan parasites which often cause infectious diarrhea and gastroenteritis, in contrast to other studies 
which have reported much higher prevalence rates $(61 \%)$ among children in public daycare centers in the State of São Paulo ${ }^{23}$. Although infection with this parasite is frequently acquired through drinking contaminated water 22 , person-to-person transmission of G. duodenalis is common in daycare settings. Low income levels and a crowded living environment are probable risk factors influencing polyparasitism and the adverse health effects associated with infection with more than one parasite 24,25 . Of the preschoolers infected with more than one parasite (13\%), almost two-thirds were from families with extremely low socioeconomic status.

After adjusting for sociodemographic factors and maternal weight or height, this study found that intestinal parasitic infections had no effect on growth (Table 6). These results differ from those of a previous study carried out in Salvador 26 as we used the growth index as the dependent variable rather than parasite type. We believe that this approach is more consistent with biological processes and other variables associated with growth were adjusted accordingly. We also observed a negative trend between G. duodenalis infection and growth which is consistent with the findings of Matos et al. 26. However, this trend was not statistically significant, perhaps because of the small sample size. It is interesting to note that sex was a predictor of certain growth indices with boys having lower BMIZ and HAZ than girls, irrespective of standard of living. Several reasons may account for these differences. Boys are known to have lower total body fat levels and faster growth rates during early childhood than girls 10 , and thus have higher energy and nutrient requirements 27,28 ; hence, it is possible that deficits in intakes of energy and growth-limiting nutrients may have been greater in boys, resulting in impaired linear growth 29 . Additionally, risk of helminth infection was twice as high in boys (Table 7), which may be because boys are more likely to play outside barefoot than girls.

Other studies regarding intestinal parasitic infections in children attending public daycare centers in Brazil 30 have focused on the transmission of Cryptosporidium sp. since, like G. duodenalis and E. histolytica, this parasite is associated with diarrhoeal illness in preschool children. Although almost five percent of children had E. histolytica/dispar cysts (E. histolytica is the principle cause of amoebiasis) 12 , only one stool sample tested positive for Cryptosporidium sp. Non-pathogenic protozoan cysts were found in a quarter of stools, which is indicative of fecaloral transmission and the possible presence of pathogenic protozoan species not detectable by concentrate microscopy, for example an E. his- tolytica infection present in low numbers of cysts or high numbers of trophozoites ${ }^{31}$.

The association between protection from helminth infection and deworming treatment reported here is not unexpected (Table 7), emphasizing the importance of providing this inexpensive treatment to preschoolers at appropriate intervals 19,32. Both Albendazole and Mebendazole can be used and are reportedly effective in the treatment of A. lumbricoides, but are less efficacious against T. trichiura. Although a larger proportion of children in the periurban gated daycare center had received deworming treatment within the six months prior to the study (Table 2), the rate of helminth infection in this group was not the lowest. This is probably because T. trichiura was the predominant parasite in these children and not A. lumbricoides. Prevalence of parasitic infections and non-pathogenic cysts was greatest in the periurban favela daycare group, probably due to the close proximity to unpaved roads, use of contaminated water sources and poor drainage and sewage connections 33 .

Unlike deworming treatment, the use of vitamin A supplements tended to provide a modest protection against $G$. duodenalis infection (Table 7). This is not the first study to report an inverse association between the use of vitamin A supplementation and G. duodenalis infection in children living in poor areas in the Northeast Region of Brazil. Lima et al. 34 also found that the rate of G. duodenalis infection was lower in children who had received vitamin A supplements. Associations between infection with Giardia and vitamin A deficiency based on low serum retinol concentrations in children have been reported in Mexico 35. Vitamin A plays a critical role in both immune function and intestinal epithelial integrity 36 and hence may stimulate immune responses against G. duodenalis.

Our study has strengths and limitations. We used the fecal concentration test which has high reproducibility (i.e., > 95\%) and is more sensitive than the commonly used Kato-Katz method 3. Constraints imposed by the available laboratory facilities meant that it was not possible to use both the sedimentation and flotation procedures and therefore the sedimentation method for parasite examination was chosen based on standard recommendations 12 . Furthermore, a sensitive and specific ELISA antigen detection test was used in addition to microcopy examination to confirm the presence of G. duodenalis and Cryptosporidium sp. 13. However, as it was possible to collect only one stool specimen per child, the results provide only a semi-quantitative assessment of the intensity of helminth infections. 
Our study sample was restricted to philanthropically-funded preschool daycare centers, thus limiting the extrapolation of results to all preschool children attending daycare centers in urban and periurban slums in Salvador. Nevertheless, the mean BMI of the children in this sample (15.4) was comparable to that of preschool children (3.0 to 5.99 years of age) living in the State of Bahia (15.3) reported in the most recent Brazilian National Nutrition Survey 37. Furthermore, given the observational nature of our study, it is not possible to establish a causal association between growth indicators and intestinal parasitic infections. Finally, future studies should collect information on the presence of domestic animals in and around the home as this is also a risk factor for transmission of G. duodenalis 21 .

In conclusion, almost $20 \%$ of our preschoolers were classified as undernourished or moderately undernourished and nearly one-third presented with an intestinal parasitic infection, notably $A$. lumbricoides, T. trichiura and/or G. duodenalis. Certain variables were more pronounced in boys than in girls. Moreover, risk of morbidity was likely to be high in approximately $50 \%$ of infected children due to the level of intensity of infection with A. lumbricoides and T. trichiura. Deworming treatment and increased vitamin A supplementation coverage in children from this age group are two simple and cost-effective strategies for reducing the rate of infection with helminths and G. duodenalis and thus decrease the risk of polyparasitism among these daycare preschoolers. Our findings also emphasize that efforts to reduce urban poverty and provide access to high quality daycare centers for families with low socio-economic status must be continued to ensure the strong growth and healthy development of these children.

\section{Resumo}

Déficit de crescimento e parasitoses são comuns entre crianças residentes em periferias. Em estudo transversal com 376 pré-escolares (3-6 anos) de creches em Salvador, Nordeste do Brasil, avaliamos fatores predisponentes para déficit de crescimento e parasitose. Obtiveram-se dados em sete creches sobre peso da criança, altura, nível socioeconômico, estado de saúde e parasitos em amostras de fezes. Prevalência de baixo peso $(-1<D P>-2)$, desnutrição e baixa estatura foram $12 \%, 16 \%$, e 6\%, respectivamente; nível socioeconômico, ordem de nascimento e peso materno foram predi tores da antropometria. Aproximadamente $30 \%$ esta vam infectados com $\geq 1$ parasita. Helmintos (17.8\%), notavelmente Trichuris trichiura (12\%) $e$ Ascaris lumbricoides (10.5\%) e protozoário Giardia duodenalis (13\%) foram os mais comuns; $<1 \%$ tinha ancilostomíase e Cryptosporidium sp.; 25\% apresentaram protozoários cistos não patogênicos. Meninos de famílias muito pobres tiveram menor crescimento e maior risco de helmintose. A desparasitação pode ser considerada uma alternativa para a redução da prevalência de parasitoses intestinais nesse grupo etário.

Pré-Escolar; Creches; Parasitos; Enteropatias Parasitárias 


\section{Contributors}

R. L. Lander designed the research project, developed the overall research plan, conducted the research, analyzed the data, wrote the draft manuscript and approved the final manuscript. A. G. Lander assisted with data collection, carried out and interpreted the microscopic assessment of fecal samples, critically revised the manuscript and approved the final version of this paper. L. Houghton contributed to data interpretation, critically revised the manuscript and approved the final version of this paper. S. M. Williams supervised the statistical analysis and data interpretation, critically revised the manuscript and approved the final version of this paper. H. Costa-Ribeiro oversaw the study, critically revised the manuscript and approved the final version of this paper. D. L. Barreto and A. P. Mattos conducted the research, critically revised the manuscript and approved the final version of this paper. R. S. Gibson participated in the design of the research project and development of the overall research plan, assisted in writing the manuscript and approved the final manuscript.

\section{Acknowledgments}

We are grateful to the Santa Casa de Misericordia and Mansão do Caminho for their support during implementation of this study, to the parents of the participating children and to the coordinators of the seven daycare centers. We would also like to thank the nutritionists from the Fima Lifshitz Research Unit of the University Hospital Prof. Edgard Santos for their assistance with data collection. Financial support was provided by the University of Otago Research Fund and Interstate Batteries (USA).

\section{References}

1. Sclar ED, Garau P, Carolini G. The 21st century health challenge of slums and cities. Lancet 2005; 365:901-3.

2. Utzinger J, Keiser J. Urbanization and tropical health: then and now. Ann Trop Med Parasitol 2006; 100:517-33.

3. Harhay MO, Horton M, Olliaro PL. Epidemiology and control of human gastrointestinal parasites in children. Expert Rev Anti Infect Ther 2010; 8: 219-34.

4. Thompson SC. Giardia lamblia in children and the child care setting: a review of the literature. J Paediatr Child Health 1994; 30:202-9.

5. Stephenson LS, Latham MC, Ottesen EA. Malnutrition and parasitic helminth infections. Parasitology 2000; 121 Suppl:S23-38.
6. Koski KG, Scott ME. Gastrointestinal nematodes, nutrition and immunity: breaking the negative spiral. Annu Rev Nutr 2001; 21:297-321.

7. Centro de Mídia Independente. Bairro da Paz 25 anos de resistência, 2007. http://www.midiainde pendente.org/pt/blue/2007/04/380475.shtml (accessed on 23/Feb/2011)

8. Issler RMS, Giugliani ERJ, Kreutz GT, Meneses CF, Justo EB, Kreutz VM, et al. Poverty levels and children's health status: study of risk factors in an urban population of low socioeconomic level. Rev Saúde Pública 1996; 30:506-11.

9. World Health Organization. Anthropometry training video: the WHO multicentre growth reference study [DVD-ROM]. Geneva: World Health Organization; 2004 
10. Kuczmarski RJ, Ogden CL, Grummer-Strawn LM Flegal KM, Guo SS, Wei R, et al. CDC growth charts: United States. Adv Data 2000; (314):1-27.

11. World Health Organization. Training course on child growth assessment, WHO child growth standards, module c: interpreting growth indicators. Geneva: World Health Organization; 2008.

12. Garcia LS. Practical guide to diagnostic parasitology. 2nd Ed. Washington DC: American Society of Microbiology Press; 2009.

13. Garcia LS, Shimizu RY. Evaluation of nine immunoassay kits (Enzyme Immunoassay and Direct Fluoresence) for detection of Giardia lamblia and Cryptosporidium parvum in human fecal specimens. J Clin Microbiol 1997; 35:1526-9.

14. Cesar JA, Mendoza-Sassi R, Horta BL, Ribeiro PR, D'Avila AC, Santos FN, et al. Basic indicators of child health in an urban area in southern Brazil: estimating prevalence rates and evaluating differentials. J Pediatr (Rio J.) 2006; 82:437-44.

15. Novaes Oliveira M, Martorell R, Phuong N. Risk factors associated with hemoglobin levels and nutrition status among Brazilian children attending daycare centers in São Paulo city, Brazil. Arch Latinoam Nutr 2010; 60:23-9.

16. Monteiro CA, Benicio MH, Konno SC, Silva AC, Lima AL, Conde WL. Causes of the decline in child under-nutrition in Brazil, 1996-2007. Rev Saúde Pública 2009; 43:1-8

17. Barros FC, Matijasevich A, Requejo JH, Giuglian E, Maranhao AG, Monteiro CA, et al. Recent trends in maternal, newborn and child health in Brazil: progress toward Millennium Development Goals 4 and 5. Am J Public Health 2010; 100:1877-89.

18. Bethony J, Brooker S, Alonico M, Geiger SM, Loukas A, Diemert D, et al. Soil-transmitted helminth infections: acariasis, trichuriasis and hookworm. Lancet 2006; 367:1521-32.

19. Cromption DWT, Nesheim MC. Nutritional impact of intestinal helminthiasis during the human life cycle. Annu Rev Nutr 2002; 22:35-59.

20. Hotez PJ. Forgotten people, forgotten diseases: the neglected tropical diseases and their impact on global health and development. Washington DC American Society of Microbiology Press; 2008.

21. Prado MS, Strina A, Barreto ML, Oliveira-Assis AM, Paz LM, Cairncross S. Risk factors for infection with Giardia duodenalis in pre-school children in the city of Salvador, Brazil. Epidemiol Infect 2003; 131:899-906.

22. Lane S, Lloyd D. Current trends in research into the waterborne parasite Giardia. Crit Rev Microbiol 2002; 28:123-47.

23. Machado RC, Marcari EL, Cristante S, Carareto CMA. Giardiasis and helminthiasis in children of both public and private day-care centers and junior and high schools in the city of Mirassol, São Paulo State, Brazil. Rev Soc Bras Med Trop 1999; 32:697-704

24. Saldiva SR, Silveira AS, Philippi ST, Torres DM, Mangini AC, Dias RM, et al. Ascaris-Trichuris association and malnutrition in Brazilian children. Paediatr Perinat Epidemiol 1999; 13:89-98.
25. Sawaya AL, Amigo H, Sigulem D. The risk approach in preschool children suffering malnutrition and intestinal parasitic infection in the city of São Paulo, Brazil. J Trop Pediatr 1990; 36:184-8.

26. Matos SMA, Assis AMO, Prado MS, Strina A, Santos LA, Jesus SR, et al. Giardia duodenalis infection and anthropometric status in preschoolers in Salvador, Bahia State, Brazil. Cad Saúde Pública 2008; 24:1527-35.

27. Butte NF, Wong WW, Hopkinson JM, Heinz CJ, Mea NR, Smith EOB. Energy requirements derived from total energy expenditure and energy deposition during the first two years of life. Am J Clin Nutr 2000; 72:1558-69.

28. World Health Organization/Food and Agriculture Organization. Vitamin and mineral requirements in human nutrition. 2nd Ed. Geneva: World Health Organization; 2004.

29. Ruz M, Castillo-Duran C, Lara X, Codoceo J, Rebolledo A, Atalah E. A 14-mo zinc-supplementation trial in apparently healthy Chilean preschool children. Am J Clin Nutr 1997; 66:1406-13.

30. Nascimento WRC, Calvalcanti IMF, Irmão JI, Rocha FJS. Presença de Cryptosporidium spp. em crianças com diarréia aguda em uma creche pública de Recife, Estado de Pernambuco. Rev Soc Bras Med Trop 2009; 42:175-8.

31. World Health Organization. Training manual on diagnosis of intestinal parasites, tutor's guide [CD ROM]. Geneva: World Health Organization; 2004.

32. World Health Organization. Prevention and control of schistosomiasis and soil-transmitted helminthiasis. Geneva: World Health Organization; 2002. (WHO Technical Report Series, 912).

33. Moraes LR, Cancio JA, Cairncross SS. Impact of drainage and sewerage on intestinal nematode infections in poor urban areas in Salvador, Brazil. Trans R Soc Trop Med Hyg 2004; 98:197-204.

34. Lima AA, Soares AM, Lima NL, Mota RM, Maciel BL, Lvalsund MP, et al. Effects of vitamin A supplementation on intestinal barrier function, growth, total parasitic, and specific Giardia spp. infections in Brazilian children: a prospective randomized, double-blind, placebo-controlled trial. J Pediatr Gastroenterol Nutr 2010; 50:309-15.

35. Quihui-Cota L, Astiazaran-Garcia H, Valencia ME, Morales-Figueroa GG, Lopez-Mata MA, Ortiz FV. Impact of Giardia intestinalis on vitamin A status in schoolchildren from northwest Mexico. Int J Vit Nutr Res 2008; 78:51-6.

36. Semba RD. Vitamin A, immunity, and infection. Clin Infect Dis 1994; 19:489-99.

37. Instituto Brasileiro de Geografia e Estatística. Pesquisa de Orçamentos Familiares 2008-2009: antropométrica e estado nutricional de crianças, adolescentes e adultos no Brasil. Rio de Janeiro: Instituto Brasileiro de Geografia e Estatística; 2010.

Submitted on 13/Nov/2011

Final version resubmitted on 15/Jun/2012

Approved on 02/Jul/2012 